\title{
Effect of enzyme location on activity and stability of trypsin and urease immobilized on porous membranes by using layer-by-layer self-assembly of polyelectrolyte
}

\author{
Sadika Guedidi ${ }^{\mathrm{a}, \mathrm{b}}$, Yilmaz Yurekli ${ }^{\mathrm{c}}$, André Deratani ${ }^{\mathrm{a}, *}$, Philippe Déjardin ${ }^{\mathrm{a}}$, Christophe Innocent ${ }^{\mathrm{a}}$, \\ Sacide Alsoy Altinkaya ${ }^{c}$, Sadok Roudesli ${ }^{\mathrm{b}}$, Ahmet Yemenicioglu ${ }^{\mathrm{c}}$ \\ a Institut Européen des Membranes, Université Montpellier 2 (ENSCM, UM2, CNRS), CC047, 2 Place Eugène Bataillon, F-34095 Montpellier Cedex 5, France \\ ${ }^{\mathrm{b}}$ Laboratoire des Polymères-Biopolymères Matériaux Organiques, Faculté des Sciences de Monastir, Avenue de l'Environnement 5019, Monastir, Tunisia \\ c Izmir Institute of Technology (IYTE), Gulbahce Koyu, Urla Izmir, Turkey
}

\section{A R T I C L E I N F O}

\section{Article history:}

Received 4 February 2010

Received in revised form 16 August 2010

Accepted 24 August 2010

Available online 24 September 2010

\section{Keywords:}

Enzyme immobilization

Layer-by-layer self-assembly

Polyelectrolyte

Catalytic membrane

\begin{abstract}
A B S T R A C T
The layer-by-layer ( $\mathrm{LbL}$ ) self-assembly of polyelectrolyte is one of the simplest ways to immobilize enzyme on membrane. In this paper, the immobilization of trypsin (TRY) and urease (URE) on polyacrylonitrile based membranes using the LbL assembly technique was presented. The studied systems consisted in bilayered assemblies with the enzyme layer as the outer layer and trilayered assemblies with the enzyme layer as the inner sandwiched layer. The membrane pore size was chosen so that the smaller enzyme TRY was mainly immobilized within the membrane and confined in the porous membrane structure while URE immobilization mainly took place at the membrane surface. No dramatic difference on reactivity was evidenced between these two enzyme locations. The catalytic activity of immobilized enzymes was found to be lower than the free ones in solution but their stability was dramatically enhanced. The higher activity was observed when the enzyme is deposited as the outer layer of the LbL assembly. On the other hand, the more stable catalytic membranes were obtained when the outer layer consists of a polyelectrolyte covering the enzyme layer.
\end{abstract}

(C) 2010 Elsevier B.V. All rights reserved.

\section{Introduction}

The use of enzyme technology is an active field of research as it enables catalysis with mild conditions, high specificity including stereo-specificity and reduced side reactions. Immobilization of enzymes displays a number of advantages over the use of their soluble counterparts. Among them, the recovery and re-use in continuous processes become possible with efficient recycling and simplicity in operation owing to easy separation of the components from the reaction mixture. Enzymes can be immobilized either by physical or chemical methods. Physical immobilization is the simplest method and more cost-effective compared to chemical one. Even if it may be less stable, it is usually considered as a good option because it can retain high catalytic activity and avoids the use of toxic bisfunctional coupling reagent as those generally employed for enzyme immobilization, as well [1].

Enzyme immobilization on the surface or within semipermeable membranes has gained growing interest to produce immobilized forms enabling controllable transport of reaction sub-

\footnotetext{
* Corresponding author. Tel.: +33 467149120; fax: +33 467149119.

E-mail address: andre.deratani@iemm.univ-montp2.fr (A. Deratani).
}

strates and products through catalytic support. This is particularly important when the product acts as an inhibitor. In this study, both functions (enzyme catalysis and membrane separation) were integrated in membrane structure by physical enzyme immobilization on polymeric ultrafiltration (UF) membranes and trypsin (TRY) and urease (URE) were used as model enzymes.

TRY belongs to the group of serine proteases [2] hydrolyzing peptide bonds in which the carboxyl groups are contributed by the lysine and arginine residues with applications in hydrolysis of protein [3] and detergent industries [4]. TRY is one of the less stable neutral proteases due to its rapid autolysis in solution. Consequently the catalytic TRY efficiency rapidly decreases with time entailing difficulty in control of reaction conditions. It is then expected that immobilization might provide a good TRY stability and reproducibility. URE is a highly efficient enzyme which catalyzes the hydrolysis of urea to ammonium and carbon dioxide. Immobilized URE can find numerous applications in the removal of urea from blood for hemodialysis operations and from fertilizer wastewater effluents, for instance [5].

The support material used in enzyme immobilization has a great impact on the performance of immobilized enzyme, since its interaction with enzyme may have an influence on the stability and kinetics as well as the non-catalytic functions, i.e. separation, con- 
trol and down streaming processes. In our work, polyacrylonitrile based membrane one of the most important polymeric materials used in biomedical field [6] was used as the support because the surface can be easily tailored [7] making this support especially attractive for immobilization.

As stressed before, the way of immobilizing enzyme on support is also of the most importance. We select physical adsorption using the polyelectrolyte layer-by-layer ( $\mathrm{LbL}$ ) technique. The LbL technique first introduced by Decher in 1991 [8], offers a general and powerful method to build tailored ultrathin films of defined thickness, composition and structure [9]. The basic process involves alternately dipping of a charged substrate into aqueous solutions of an anionic and a cationic polyelectrolyte. During the dipping stage, adsorption of polyelectrolyte leads to a charge inversion of surface due to an overcompensation phenomenon that enables subsequent adsorption by the oppositely charged polyelectrolyte [10,11]. A large variety of polymers such as synthetic polyelectrolytes, proteins, nucleic acids have been employed to assemble multilayers [12].

The LbL method has recently received much attention in immobilizing biomolecules especially for biosensor applications $[13,14]$ and biocatalysis [15]. To our best knowledge, there are only few reports dealing with enzyme immobilization on membranes as support using LbL assembly. For instance Nguyen et al. [16] have showed the feasibility of immobilizing glucose oxidase (GOx) by using adsorption of an intermediate polyelectrolyte layer on an oppositely charged membrane. The method has been demonstrated to offer a versatile route for preparing enzyme supported membranes, the activity of which depended on the support likely due to its pore size. Using the same approach, the Battacharyya's group $[17,18]$ has prepared catalytic membrane by enzyme immobilization within the pore domain of microfiltration (MF) membrane. As expected, supported enzyme stability was higher compared to the free GOx. On the other hand, the amount of immobilized enzyme and stability was found to be higher when the protein and the support are oppositely charged. In both of these studies, the outer layer consists of the enzyme layer and the LbL deposition acts as an anchor for the biomacromolecule. Caruso et al. $[19,20]$ have prepared enzyme modified membranes using alternative adsorption of peroxidase-poly(sodium 4-styrenesulfonate) complex and a positively charged polyelectrolyte within MF membrane pores. The membrane catalytic activity was found to increase up to a certain number of bilayers beyond which it is assumed that membrane pore blockage took place. In this case the enzyme is located within the successive layers and is an inner part of the LbL film. Gabrovska et al. first deposited chitosan onto polyacrylonitrile to prepare composite membranes and then immobilized URE covalently onto chitosan layer using gluteraldehyde as a cross linking agent [21]. It has been found that the presence of amino groups facilitated the immobilization of URE onto the composite membrane. Disawal et al. [22] have used LbL self-assembly to build multicomponent thin films containing two polyions, poly(dimethyl-diallyl ammonium chloride and Na-poly(styrene sulfonate) and two enzymes, URE and arginase, on gold electrode resonator. The influences of position and number of enzyme layers on the catalytic activity were investigated. The results have shown that the position of enzyme layers in the multilayer structure is the main factor influencing the activity of the films. As opposed to limited number studies focused on URE immobilization on membranes using LbL technique, covalent immobilization and non-specific adsorption of URE on various supports have been frequently reported in literature. A review of these studies was given by Krajewska [23].

As the LbL technique enables the enzyme environment to be precisely tuned, the design of efficient reactive membranes needs to get detailed insight on the effect of environment on the enzyme activity and stability. The objectives of this report are to investi- gate the effect of the enzyme location on the activity and stability. For this purpose, we examine the use of LbL method for preparing catalytic TRY and URE immobilized membranes in bilayered and trilayered enzyme polyelectrolyte assemblies. The effect of enzyme location as the outer and the inner sandwiched layer on the activity and stability can then be examined. On the other hand, it is expected that the small size of TRY should enable its facile penetration in an UF membrane pores whereas URE should stay at the top surface and, consequently, immobilization of TRY should take place mainly within the pore domain while that of URE should be onto the membrane surface. It is assumed that this combined approach can help us to tailor catalytic enzyme membrane with improved architecture.

\section{Materials and methods}

\subsection{Materials}

Trypsin (23.8 kDa) from bovine pancreas type XII-S (EC3.4.21.4 and $\geq 9000$ BAEE $\mathrm{U} \mathrm{mg}^{-1}$ solid), Jack bean URE ( $545 \mathrm{kDa}$ ) type III (EC3.5.1.5 and U1500-20KU, 1.18 G solid, $17 \mathrm{U} \mathrm{mg}^{-1}$ solid), Bradford reagent ( $B$ 6916) for the determination of URE amount, $\mathrm{N}_{\alpha}$-benzoylDL-arginine- $p$-nitroanilide (BAPNA) and urea were purchased from Sigma. Trizma hydrochloride and sodium phosphate buffer solutions $\left(\mathrm{NaH}_{2} \mathrm{PO}_{4}, \mathrm{Na}_{2} \mathrm{HPO}_{4}\right)$ were purchased from Fluka. Organic solvents and all other reagents were of analytical grade. The solutions were prepared with purified water (Milli-Q water, resistance $18 \mathrm{M} \Omega \mathrm{cm}$ ).

The TRY purity was determined to be $90 \%$ using chromatography on a Superose 12 column and that of URE to be $3.47 \%$ using the Bradford method [24]. According to the latter method, $1 \mathrm{~mL}$ of enzyme solution is mixed with $1 \mathrm{~mL}$ of Bradford reagent. Followed by $10 \mathrm{~min}$ of incubation, the concentration is determined at $595 \mathrm{~nm}$ using UV/VIS spectrophotometer.

\subsection{Membranes}

Polyacrylonitrile based membrane (denoted as AN69) of $15 \mu \mathrm{m}$ thickness is produced by copolymerization of acrylonitrile with sodium methallyl sulfonate. AN69 is negatively charged due to the presence of the ionized sulfonate groups. It can be further modified by a positively charged polyelectrolyte to yield a positively charged membrane. This was performed by polyethyleneimine (PEI) adsorption and the membrane obtained was denoted as (AN69-PEI). Both these membranes were kindly provided by Gambro-Hospal Co. (Meyzieu, France) [25]. The membranes were washed with a buffer solution before contacting with enzyme solution.

\subsection{Preparation of reactive enzyme membranes using layer-by-layer deposition}

$1 \mathrm{~g} \mathrm{~L}^{-1}$ aqueous solutions of sodium alginate (ALG) at $\mathrm{pH} 6$ and $\mathrm{PEI}$ at $\mathrm{pH} 8$ were used as the anionic and cationic polyelectrolyte, respectively. TRY in $0.1 \mathrm{M}$ Trizma buffer at $\mathrm{pH} 8$ containing $0.02 \mathrm{M} \mathrm{CaCl}_{2}$ was applied as the positively charged enzyme (isoelectric point $($ IP $)=10.1$ ) [2]. URE in $0.05 \mathrm{M} \mathrm{Na-phosphate} \mathrm{buffer}$ was applied as the negatively charged enzyme at $\mathrm{pH} 7.4$, which is above its IP (=5.0) [26].

As depicted in Fig. 1, the reactive TRY membranes were fabricated by successive immersion of (AN69-PEI) membrane in ALG and in TRY giving the (AN69-PEI-ALG-TRY) membrane and in ALG, TRY and ALG giving the (AN69-PEI-ALG-TRY-ALG) membrane. Reactive URE membranes (AN69-PEI-URE and AN69-PEI-URE-PEI) were prepared using the same approach. Each stage of adsorption was 


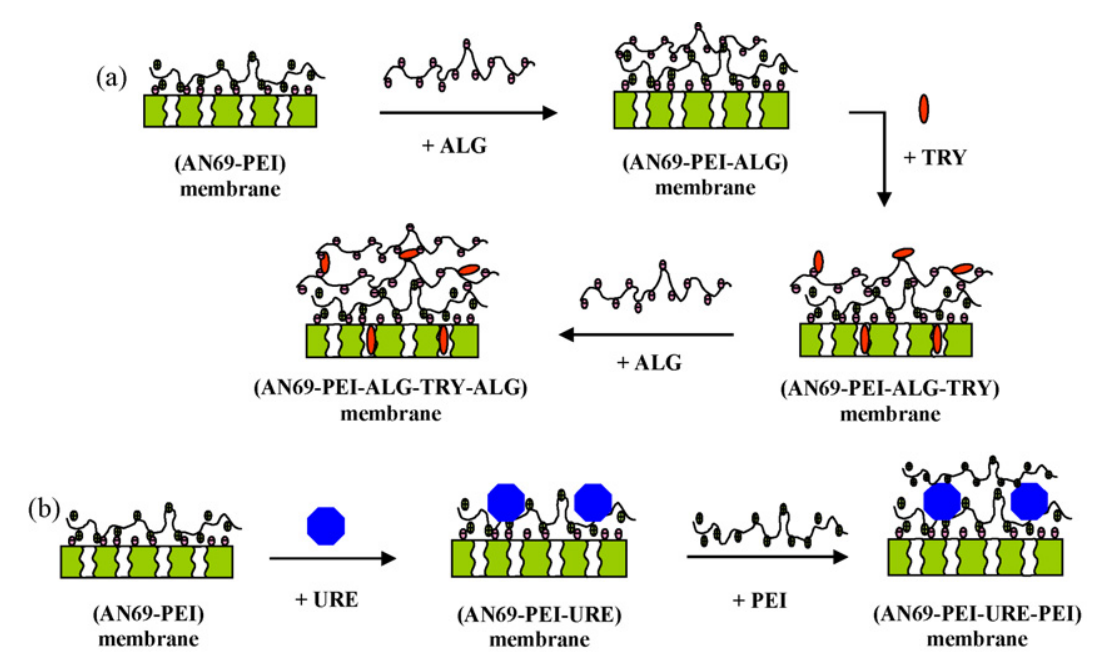

Fig. 1. Enzyme immobilized in multilayer assembly: (a) reactive TRY membranes; (b) reactive URE membranes.

followed by rinsing the membrane in the corresponding buffer solution to remove excess of polyelectrolyte.

\subsection{Determination of free and immobilized enzyme activity}

TRY hydrolyzes BAPNA into two products, including $\mathrm{N}_{\alpha}$-benzoyl arginine and the yellow colored $p$-nitroaniline ( $p$-NA). The $p$-NA has a maximal absorbance at $380 \mathrm{~nm}$ as shown in Fig. 2 . The wavelength of $410 \mathrm{~nm}$ was chosen in order to prevent any interference owing to the absorption by non-hydrolyzed BAPNA [27]. The proteolytic activity of free TRY was determined by monitoring the catalytic hydrolysis of BAPNA as a substrate. The buffer solution used is $0.1 \mathrm{M}$ Trizma and $0.02 \mathrm{M} \mathrm{CaCl}_{2}(\mathrm{pH} 8)$ was added to protect the enzyme from autolysis [28]. $20 \mu \mathrm{L}$ of $1 \mathrm{mg} \mathrm{mL}^{-1} \mathrm{TRY}$ was added in $4 \mathrm{~mL}$ of $1 \mathrm{mM}$ BAPNA (at pH 8 ). The specific activity of TRY $\left(A_{\mathrm{TRY}}\right.$ in

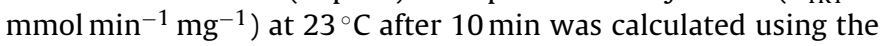
following equation:

$A_{\mathrm{TRY}}=\frac{A \times V}{t \times \varepsilon \times l \times m}$

where $A$ is the absorbance value of the product at $410 \mathrm{~nm}, V$ the volume of sample $(\mathrm{mL}), t$ the reaction time (min), $\varepsilon$ the extinction coefficient of $p$-NA at $410 \mathrm{~nm}\left(\mathrm{M}^{-1} \mathrm{~cm}^{-1}\right), l$ the optical path $(\mathrm{cm})$ and $m$ is the amount of free/immobilized enzyme ( $\mathrm{mg}$ ). The activity of immobilized TRY ( $\mathrm{mmol} \mathrm{min}^{-1} \mathrm{mg}^{-1}$ ) was determined from a given surface area of membrane using the same experimental conditions.

URE catalyzes the hydrolysis of urea to ammonium and carbon dioxide according to:

$\mathrm{H}_{2} \mathrm{NCONH}_{2}+\mathrm{H}_{2} \mathrm{O} \stackrel{+\mathrm{URE}}{\longrightarrow} 2 \mathrm{NH}_{3}+\mathrm{CO}_{2}$

In the activity measurements, the reaction time, volume and temperature were fixed as $30 \mathrm{~min}$ (see Supplementary material), $5 \mathrm{~mL}$ and $37^{\circ} \mathrm{C}$ respectively for both free and immobilized forms of the URE. In the case of free URE, the catalytic reaction was carried out by adding $0.5 \mathrm{~mL}, 1 \mathrm{mg} \mathrm{mL}^{-1}$ of enzyme product into $4.5 \mathrm{~mL}$ of $10 \mathrm{mM}$ urea solution which was prepared in $50 \mathrm{mM}$ Na-phosphate buffer at $\mathrm{pH}$ 7.4. At the end of $30 \mathrm{~min}$, reaction was stopped by adding $2.5 \mathrm{~mL}$ of acetic acid solution $(10 \%, \mathrm{v} / \mathrm{v})$. In the case of immobilized form of URE, a small piece of catalytic membrane was put into urea solution whose conditions were the same as in free form of URE. A shaker adjusted to $100 \mathrm{rpm}$ was used during reaction. The concentration of ammonia formed during catalytic reaction was determined by Weatherburn method [29]. According to this method, $20 \mu \mathrm{L}$ aliquot of the final reaction mixture was poured into a tube which consists of $5 \mathrm{~mL}$ of reagent-A ( $5 \mathrm{~g}$ of phenol with $25 \mathrm{mg}$ of sodium nitroprusside diluted to $500 \mathrm{~mL}$ with water). After shaking gently, $5 \mathrm{~mL}$ of reagent-B (2.5 g of sodium hydroxide and $4.2 \mathrm{~mL}$ of sodium hypochlorite diluted to $500 \mathrm{~mL}$ with water) was added. The mixture was then incubated at $37^{\circ} \mathrm{C}$ for $20 \mathrm{~min}$. At the end, the color change which gives a relation to the liberated ammonium concentration was detected at a wavelength of $625 \mathrm{~nm}$. The linear growth of the product during $30 \mathrm{~min}$ reaction has been observed, therefore, the specific activity of URE was calculated based on number of moles of $\mathrm{NH}_{3}$ produced in $30 \mathrm{~min}$.

$A_{\mathrm{URE}}=\frac{n_{\mathrm{NH}_{3}}}{t \times m}$

where $n_{\mathrm{NH}_{3}}$ is the mole number of $\mathrm{NH}_{3}$ produced in $30 \mathrm{~min}$ ( $\mathrm{mmol}), t$ the reaction time ( $\min )$ and $m$ is the amount of the free/immobilized enzyme (mg).

Replicate measurement of enzymatic activity using samples coming from different immobilization batches were carried out. The reproducibility in specific activity was found to be excellent (within a $\pm 5 \%$ range).

The amount of enzyme adsorbed on the membrane $(\mathrm{mg})$ was determined by difference between the initial enzyme amount ( $\mathrm{mg}$ ) in the solution before contacting with the membrane and that after a given time of contact. The adsorbed amount of enzyme was then converted to surface density by dividing it to the surface area of the membrane to give the interfacial concentration $\Gamma\left(\mathrm{mg} \mathrm{m}^{-2}\right)$. Kinetics of enzyme adsorption is the evolution of $\Gamma$ as a function of contact time and adsorption isotherm is the evolution of $\Gamma$ as a function of the enzyme concentration in $\mathrm{mg} \mathrm{mL}^{-1}$ at equilibrium determined to be $3 \mathrm{~h}$ for TRY and $24 \mathrm{~h}$ for URE from kinetic measurements.

In the case of TRY, a $4 \mathrm{~cm} \times 4 \mathrm{~cm}$ piece of membrane was immersed into $10 \mathrm{~mL}$ of TRY solution with a concentration in the range of $0.1-3 \mathrm{mg} \mathrm{mL}^{-1}\left(23^{\circ} \mathrm{C}\right)$. The adsorbed amount of TRY was followed during immobilization by measuring the concentration of TRY in the solution using BAPNA titration.

In the case of URE, a $6 \mathrm{~cm} \times 6 \mathrm{~cm}$ piece of membrane was immersed into $20 \mathrm{~mL}$ of URE solution with a concentration in the range of $0.03-0.14 \mathrm{mg} \mathrm{mL}^{-1}\left(4^{\circ} \mathrm{C}\right)$. The adsorbed amount of URE was followed during immobilization by measuring the concentration of URE in the solution using Bradford method [24]. 

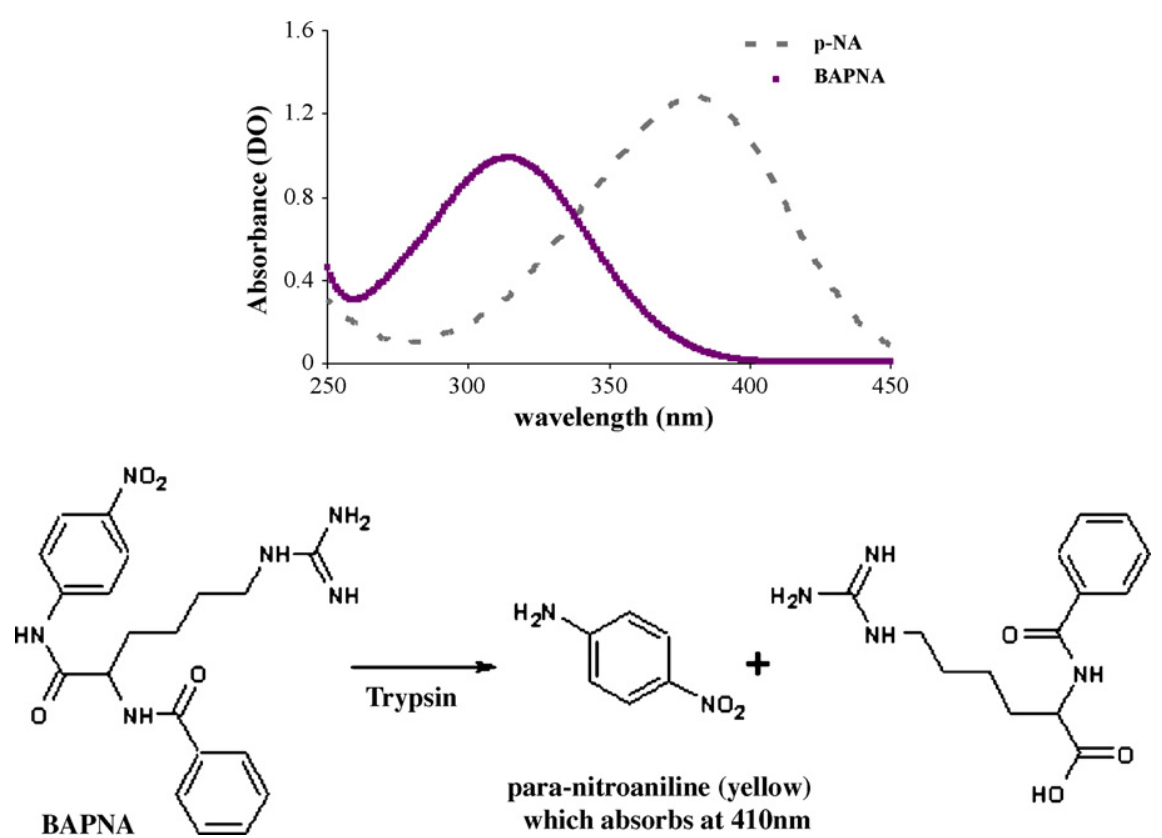

Fig. 2. Measurement of the TRY activity using BAPNA as substrate.

\subsection{Scanning electron microscopy (SEM)}

The surface and cross-section morphology of the unmodified and enzyme modified membranes were examined by a cold cathode emission scanning electron microscope (Hitachi S4500 , resolution of $1.5 \mathrm{~nm}$ at $15 \mathrm{kV}$ ). For this purpose, membrane samples were dried at room temperature, and then covered with a thin layer of Pt by sputter coating before SEM analysis. The mean pore size was estimated from a selection of the ca. 30-50 more representative pores by image treatment of the cross-section pictures using Axone (Newtec) imaging analysis software.

\subsection{Stability of the immobilized enzyme}

The activity of free and immobilized enzyme during storage at $4{ }^{\circ} \mathrm{C}$ were measured at certain times with the experimental conditions given above. An aliquot of free enzyme sample was taken for each measurement whereas in the case of immobilized enzyme the whole sample was periodically assayed. The residual activity was defined as the fraction of activity recovered after storage period of the enzyme preparations compared to activity at time zero.

\section{Results and discussion}

\subsection{Preparation of enzyme immobilized membrane}

Kinetics of enzyme adsorption on AN69 and polyelectrolyte modified membranes were first studied. Fig. 3 shows the change in the interfacial concentration ( $\Gamma$ expressed with respect to the apparent external surface area of the membrane considered as flat) of immobilized enzyme as a function of time. $\Gamma$ is an increasing function of adsorption time until a plateau, which might correspond to dynamic balance between adsorption and desorption. It is reached after about $3 \mathrm{~h}$ for TRY and more than $8 \mathrm{~h}$ for URE. Two regimes can be distinguished during the adsorption of enzyme. The first one corresponds to the fast occupation of the surface initially uncovered by the enzyme and the quantity of adsorbed enzyme varied rapidly. It was followed by a second regime where the quantity of enzyme adsorbed varied more slowly likely due to surface rear- rangement. In the rest of this study, the immobilization time was fixed at $3 \mathrm{~h}$ for TRY and $24 \mathrm{~h}$ for URE.

The immobilization of positively charged TRY on oppositely charged AN69 and (AN69-PEI-ALG) membranes was favored mainly due to electrostatic interaction. This accounts for the observation that TRY adsorption was similar for the two membranes. On the other hand, URE $(\mathrm{IP}=5.0)$ is mainly negatively charged at $\mathrm{pH}$
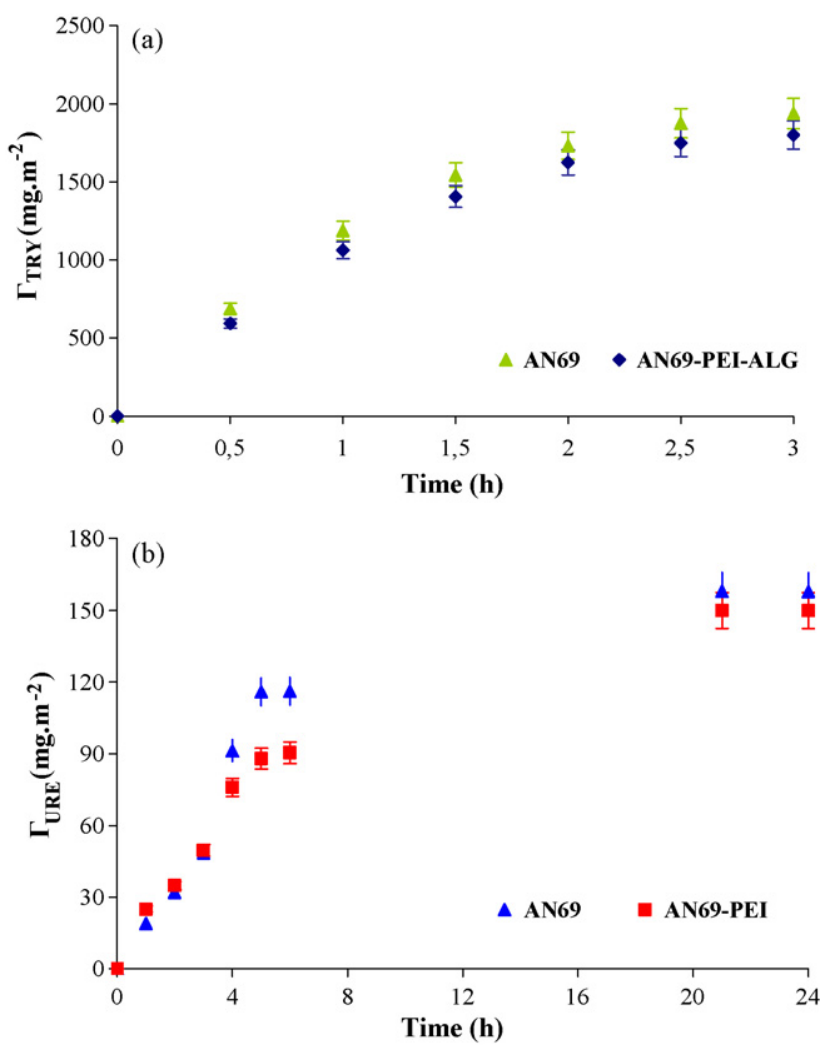

Fig. 3. Enzyme adsorption kinetics on the studied membranes: (a) TRY; (b) URE. $\Gamma$ : interfacial concentration related to the membrane external apparent surface area considered as flat. 

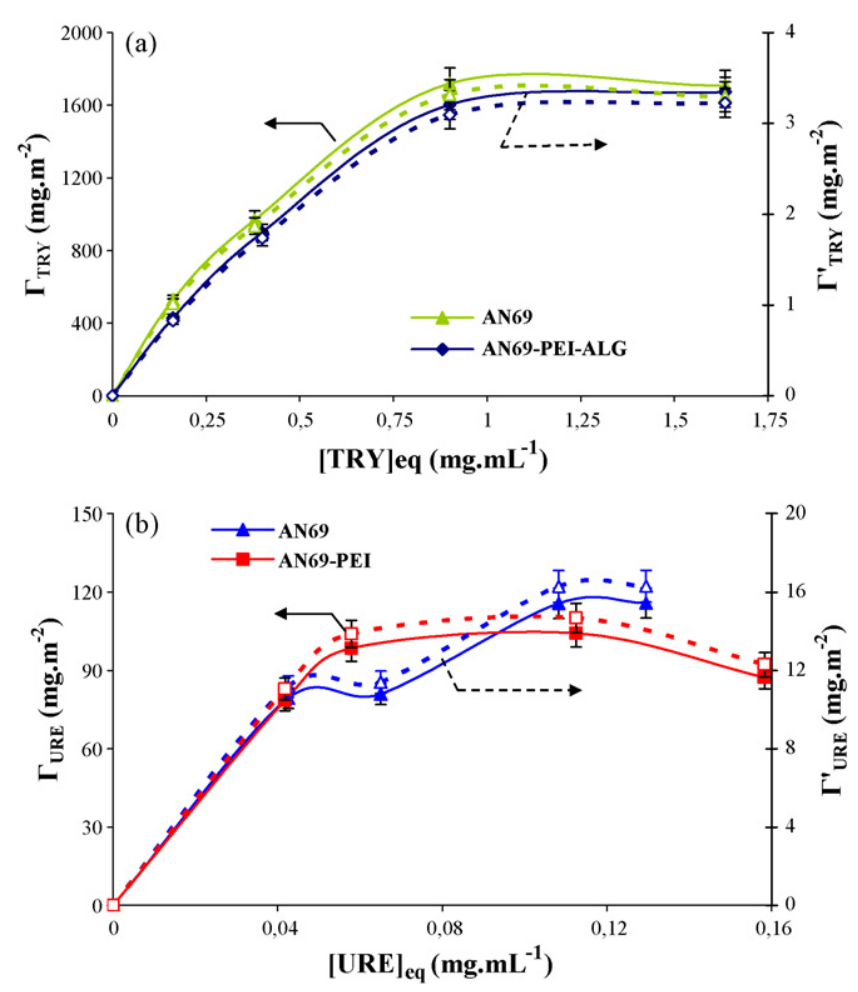

Fig. 4. Enzyme adsorption isotherms on the studied membranes: (a) TRY; (b) URE. $\Gamma$ : interfacial concentration related the membrane external apparent surface area considered as flat. $\Gamma^{\prime}$ : theoretical interfacial concentration related to the total surface area accessible to enzyme (Eq. (3)).

7.4. However, URE also bears positive charges at this $\mathrm{pH}$ since it has been reported that URE contains about 48 lysine residues [30] and its $\mathrm{p} K_{\mathrm{a}}$ value is given as 10.8 in Ref. [31]. Although binding of URE by both negatively and positively charged surfaces was expected, we thought that the amount of protein adsorbed on the surface with the same charge would be weak [14]. Surprisingly, the results showed that the adsorbed amount of URE was slightly higher on the negatively charged AN69 than on the positively charged (AN69-PEI) membrane. It is assumed that additional interactions (hydrogen bonding, hydrophobic interaction) might be the main driving force in the case of URE adsorption on the polyacrylonitrile matrix of the AN69 membrane, while they are shielded by the PEI layer in the case of (AN69-PEI).

Fig. 4 presents the adsorption isotherms of both TRY and URE on the different studied membranes. In the case of TRY (Fig. 4(a)), $\Gamma$ levels off to a plateau value for equilibrium TRY concentration of $1 \mathrm{mg} \mathrm{mL}^{-1}$. On the other hand, though the data observed for URE were more scattered due to the small amount of adsorbed enzyme (Fig. 4(b)), a plateau can also be observed for solution concentration of $0.05-0.11 \mathrm{mg} \mathrm{mL}^{-1}$. The $S$ type adsorption appeared on AN69 membrane may originate from the weak forces, other than electrostatic interaction (both enzyme-membrane carry net negative charges at physiological $\mathrm{pH}$ ). The weakness of the forces between URE and the surface of the membrane might cause the uptake at low concentrations to be small, but once an enzyme molecule has become adsorbed, the enzyme-enzyme forces will promote the adsorption of further molecules - a cooperative process. This non-specific adsorption results in clusters on certain areas of the membrane in a nucleation growth type of the process. Although the plateau for URE adsorption on AN69-PEI occurs at the concentration of $0.05 \mathrm{mg} \mathrm{mL}^{-1}$, URE concentration for further immobilization on that membrane surface was also selected as $0.11 \mathrm{mg} \mathrm{mL}^{-1}$ in order
Table 1

Maximum interfacial concentrations of immobilized TRY and URE on AN69 membrane.

\begin{tabular}{llc}
\hline & TRY & URE \\
\hline Apparent $\Gamma_{\max }\left(\mathrm{mg} \mathrm{m}^{-2}\right)$ & 1710 & 116 \\
$\Gamma_{\max }^{1}\left(\mathrm{mg} \mathrm{m}^{-2}\right)^{\mathrm{a}}$ & 3.3 & 16.3 \\
$\Gamma_{\max } / \Gamma_{\max }^{1}$ & 518 & 7.1 \\
\hline a Calculated from Eq. (3). & &
\end{tabular}

to compare the influence of the support type on the immobilization efficiency in the same conditions.

The maximum amount of immobilized TRY corresponds to a maximum value for the interfacial concentration $\left(\Gamma_{\max }\right)$ of $1710 \mathrm{mg} \mathrm{m}^{-2}\left(71.8 \mu \mathrm{mol} \mathrm{m}^{-2}\right)$ whereas that of URE is about $116 \mathrm{mg} \mathrm{m}^{-2}\left(0.21 \mu \mathrm{mol} \mathrm{m}^{-2}\right)$. These data reveal a huge discrepancy of immobilized amount between both enzymes that can be explained by a difference of the surface area available for immobilization. It was expected that TRY should be immobilized on the external surface and within the pores since TRY passes freely through the membranes as proved by UF experiments. By contrast, URE is quantitatively retained by the membrane so that the surface area available should be limited to the external surface and likely to some large surface pores. Based on this hypothesis, the theoretical interfacial concentrations of the both enzymes, $\Gamma^{\prime}\left(\mathrm{mg} \mathrm{m}^{-2}\right)$ were calculated as indicated in Eq. (3), by assuming that adsorbed enzyme molecules form a hexagonal packing:

$\Gamma^{\prime}=\frac{m}{2 r \sqrt{3 r^{2}}}$

where $m$ is the mass of the enzyme adsorbed $(\mathrm{mg})$ and $r$ is the radius of the enzyme $(\mathrm{m})$ determined using the molecular dimensions of TRY and URE. The enzyme molecule can be approximated as an ellipsoid with dimensions of $4.8 \mathrm{~nm} \times 3.7 \mathrm{~nm} \times 3.2 \mathrm{~nm}$ for TRY [32] and $7.5 \mathrm{~nm} \times 8 \mathrm{~nm} \times 8 \mathrm{~nm}$ for URE [33]. Dashed lines in Fig. 4 represent the adsorption isotherms expressed as $\Gamma^{\prime}$ and Table 1 lists the $\Gamma_{\max }$ (apparent interfacial concentration) and $\Gamma_{\max }^{\prime}$ (calculated interfacial concentration).

$\Gamma_{\max }^{1}$ depends on the total surface area accessible to the corresponding enzyme which is sum of the external surface area of the membrane and part of the pore surface area. The ratio $\Gamma_{\max } / \Gamma_{\max }^{\prime}$ (Table 1 ) describes the gap between the apparent and effective surface area. A value of 500 is calculated for TRY considering a membrane thickness of $15 \mu \mathrm{m}$ and 7 for URE. The location of enzyme immobilization is then proven to be different as URE is only located at the superficial part of the membrane whereas TRY is immobilized inside he membrane pores, as well.

The morphological change through TRY immobilization was observed by SEM to bring additional evidence of its adsorption within the membrane porosity. The cross-sectional observation shows that AN69 has a homogeneous porous structure enabling a large internal surface area available for the enzyme immobilization. Enlargements presented in Fig. 5 suggest that the membrane pore size decreased upon TRY immobilization. The mean average measurement of pore size estimated using image treatment software confirms this assumption since the pore radius decreased after TRY immobilization (Table 2). By contrast, the same imaging analysis for URE modified membrane does not show any difference compared to that of the unmodified AN69 indicating that URE is mainly immobilized at the membrane surface. It should be noted that the estimated mean pore radius determined by this approach is only an indicative value as it was difficult to obtain straight membrane cross-sections. However, the same trend is observed for the different studied TRY immobilized membranes (Table 2). The successive polyelectrolyte adsorption also decreased the pore radius but to a smaller extent. This effect is likely due to the fact that TRY keeps more or less its glob- 

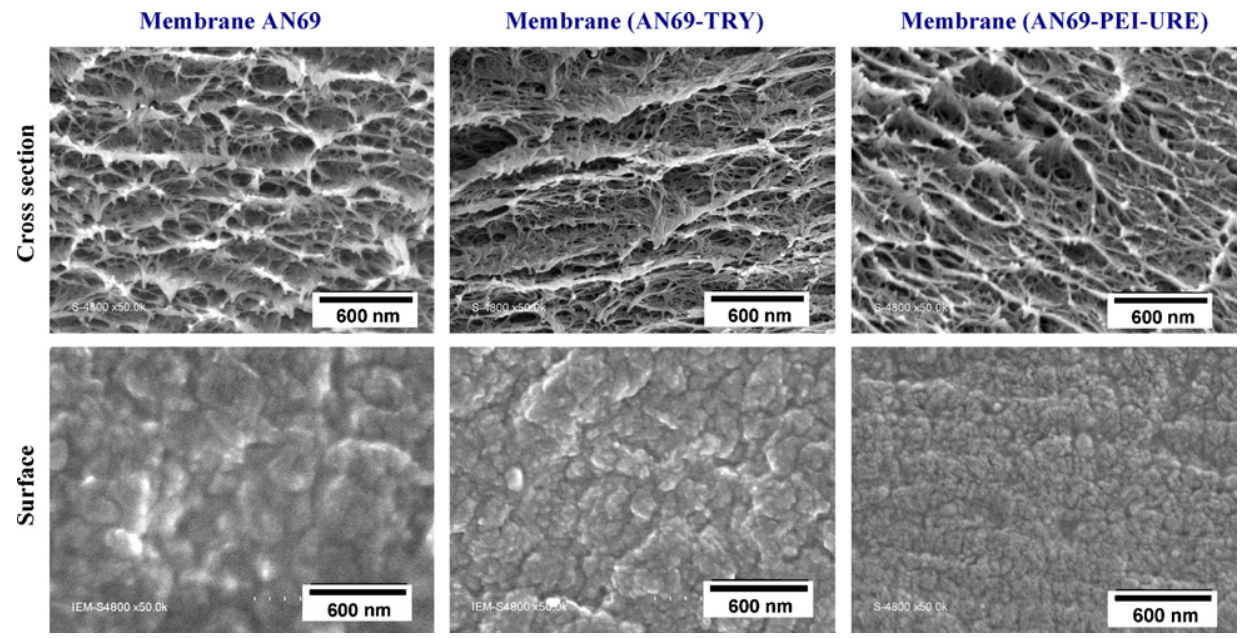

Fig. 5. SEM cross-section observation of AN69 and modified membranes. Magnification 50K $\times$.

Table 2

Mean average pore radius of the studied membranes as estimated from the SEM observations using imaging software (see Section 2.6).

\begin{tabular}{ll}
\hline Membranes & Mean average pore radius (nm) \\
\hline AN69 & $20 \pm 6$ \\
AN69-TRY & $13 \pm 4$ \\
AN69-PEI-URE & $21 \pm 1$ \\
AN69-PEI-ALG-TRY & $13 \pm 4$ \\
AN69-PEI-ALG-TRY-ALG & $11 \pm 4$ \\
\hline
\end{tabular}

ular shape compared to the flat adsorption of polyelectrolytes [34].

On the other hand, surface observation of the unmodified AN69 and enzyme modified membranes revealed that URE immobilization clearly induced change of the membrane surface morphology. The effect is much less marked in the case of TRY probably due to the smaller size of TRY compared to that of URE.

\subsection{Activity of immobilized enzymes}

Immobilization onto support often results in decreasing the enzyme activity by lowering the substrate accessibility to the active sites. In this part, the catalytic activity of immobilized enzyme is determined by the amount of the formed product at equilibrium and compared to that of the free corresponding enzyme. The reactive membranes were tested in batch experiments to avoid competition between thermodynamics and kinetics as it can be observed in filtration where the residence time of substrate in the proximity of the catalytic site has to be taken into account. It is important to note that no convective flux was applied through the pores. The absolute specific activity of immobilized enzymes was found to be about $1-10 \%$ that of the free ones in solution (Table 3 ).

The $\mathrm{pH}$-activity profiles of free and immobilized enzymes were evaluated in the range 5-9 (Fig. 6). Actually, the results are presented using the relative activity in order to get clear insight for

Table 3

Specific activity of immobilized TRY and URE on AN69 membrane.

\begin{tabular}{ll}
\hline Membranes & Specific activity $\left(\mathrm{mmol} \mathrm{min}^{-1} \mathrm{mg}^{-1}\right)$ \\
\hline AN69-TRY & 2.50 \\
AN69-PEI-ALG-TRY & 3.64 \\
AN69-PEI-ALG-TRY-ALG & 3.34 \\
AN69-URE & $9 \times 10^{-3}$ \\
AN69-PEI-URE & $20 \times 10^{-3}$ \\
AN69-PEI-URE-PEI & $5 \times 10^{-3}$ \\
\hline
\end{tabular}
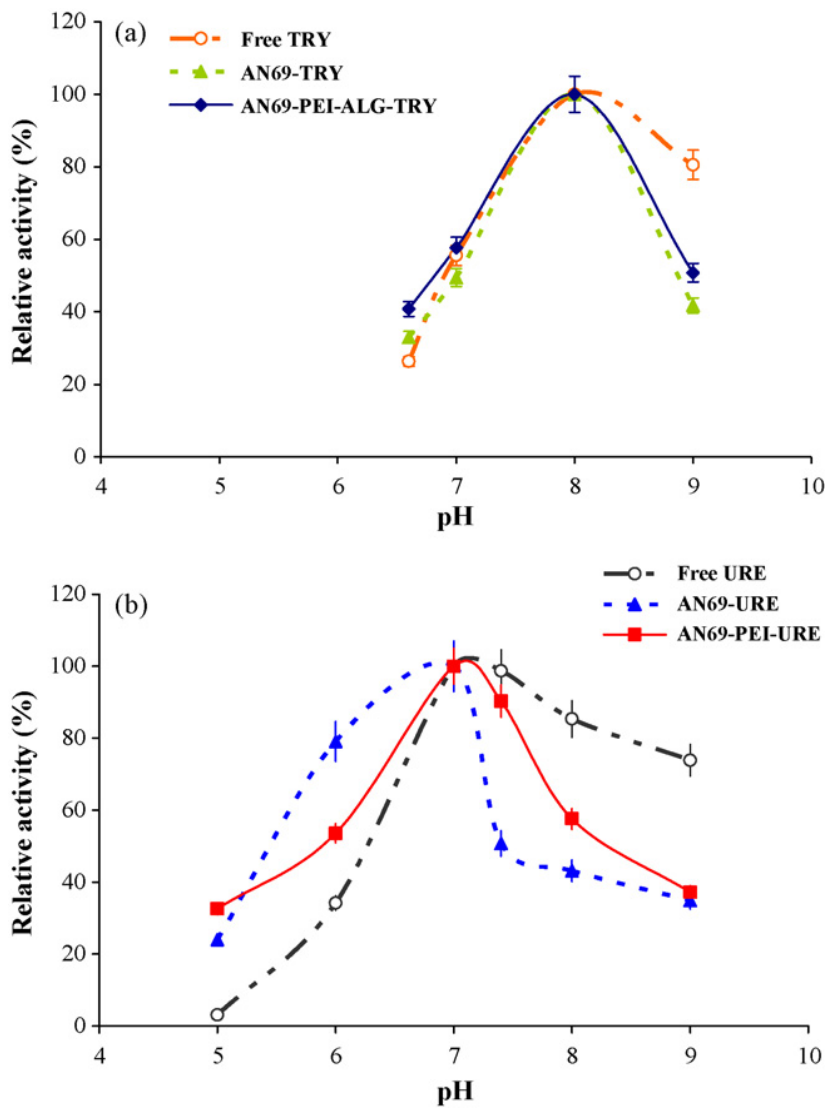

Fig. 6. pH variation of the catalytic activity for the free and immobilized enzymes: (a) TRY; (b) URE.

comparison. The relative enzyme activity was calculated using the following expression:

Relative activity $=\frac{\text { Absolute activity at } \mathrm{pH}_{i}}{\text { Absolute activity at optimum } \mathrm{pH}} \times 100(4)$

As it can be seen, only a very sharp domain gives rise to the maximal activity and going on to acidic and alkaline environment dramatically decreases the relative activity. TRY belongs to the alkaline protease group. It was reported that conformational changes affect the appropriate binding of enzyme to substrate [35]. The similar activity variation of both free and immobilized TRY at tested 

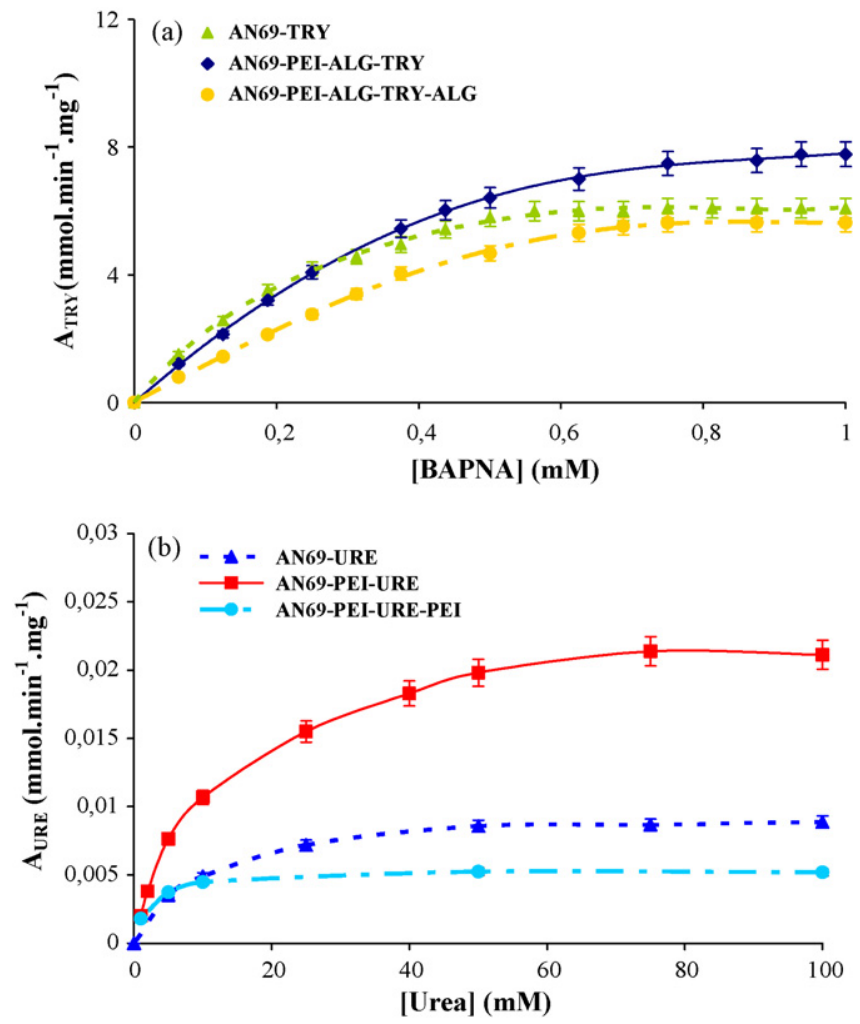

Fig. 7. The specific activity of the studied membranes as a function of substrate concentration: (a) TRY; (b) URE.

$\mathrm{pH}$ range suggests that the adsorption does not entail significant change in the enzyme conformation (Fig. 6(a)). The same optimum $\mathrm{pH}$ about 8 was observed that is in accordance with literature data for the free TRY [36].

In the case of URE, the optimum $\mathrm{pH}$ for both native and immobilized enzyme was found to be at about 7 (Fig. 6(b)). The inhibitory action of phosphate buffer below $\mathrm{pH} 7.0-7.5$ has been reported in literature and ascribed to $\mathrm{H}_{2} \mathrm{PO}_{4}{ }^{-}$ion [37]. The $\mathrm{pH}$ dependent inhibitory strength decreases with an increase in $\mathrm{pH}$ and stops at $\mathrm{pH}$ 7.0-7.5. The difference between $\mathrm{pH}$-activity curves of URE in free and immobilized forms may come from unequal charge distribution of small molecules in the bulk and in the vicinity of enzyme molecules. The $\mathrm{pH}$ of the microenvironment may have variation from the bulk solution either by the enzymatic reactions or by the electrostatic interactions between those small ions and charge molecules on the support. In addition, the mass transfer limitation may also influence the shape of the $\mathrm{pH}$-dependence curve.

It should be noted that immobilized form of URE retains higher activity at lower $\mathrm{pH}$ than the soluble counterpart. For the rest of the study, we will use $\mathrm{pH} 8$ and 7.4 for evaluation of the activity of immobilized TRY and URE, respectively. In the latter case, the choice of $\mathrm{pH} 7.4$ was primary important for performance in hemodialysis applications since this $\mathrm{pH}$ correspond to physiological $\mathrm{pH}$ of blood.

The maximum reaction rate reflects the catalysis efficiency as it indicates the substrate concentration at which the enzyme reaches its maximum activity (saturation). Plotting the enzyme specific activity as a function of the substrate concentration gives a hyperbolic curve as shown in Fig. 7 for enzyme immobilized membranes [38]. The kinetic parameters $V_{\max }$ and $K_{\mathrm{M}}$ values were calculated from the saturation curves presented in Fig. 7 and compared with those of the free enzymes (see Supplementary materials).

Two main trends can be inferred from these data: (i) enzyme immobilization onto a polyelectrolyte layer (outer location) results in a higher catalytic activity than that of enzyme directly immo-

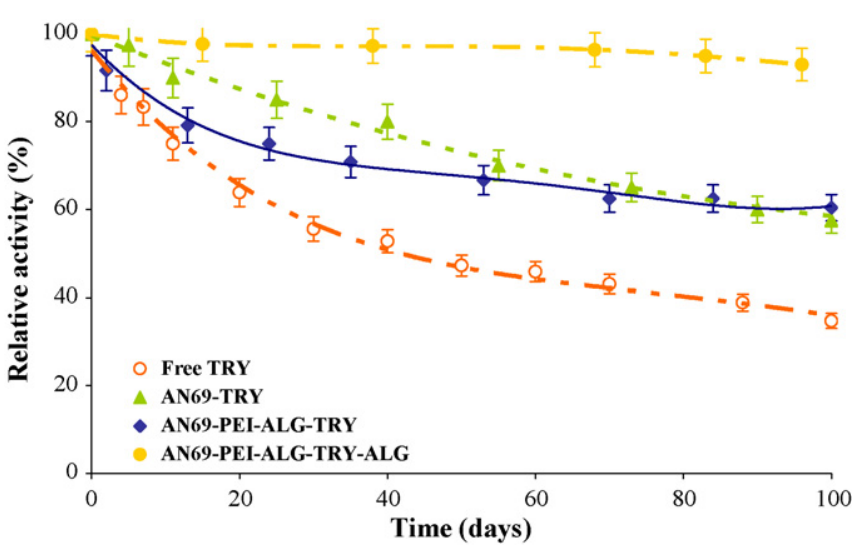

Fig. 8. The storage stability of the free and immobilized TRY over time.

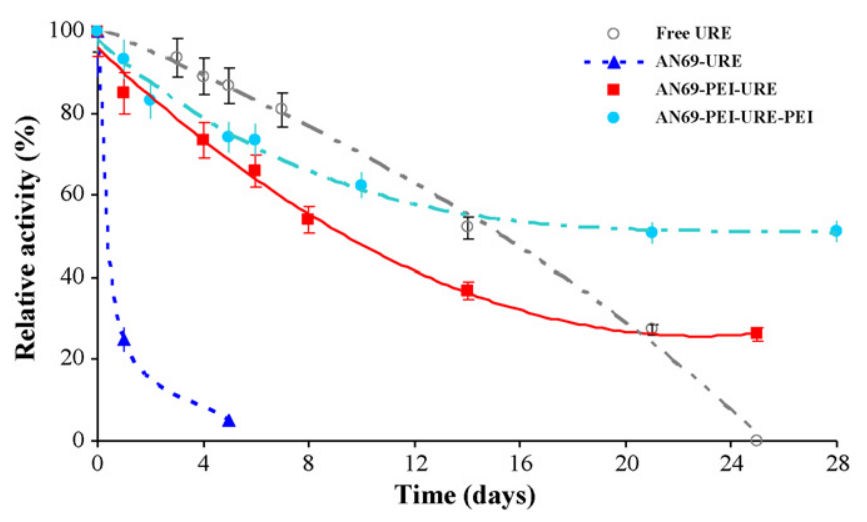

Fig. 9. The storage stability of the free and immobilized URE over time.

bilized on the AN69 membrane clearly indicating the beneficial effect of a polyelectrolyte environment; (ii) enzyme immobilization in between two polyelectrolyte layers (inner location) decreases the activity compared to the previous case likely due to the diffusion limited accessibility of the catalytic site. The latter effect much more pronounced with a $75 \%$ decrease of activity in the case of URE might be explained by the enzyme rearrangement burying the active center during the deposit of the outer polyelectrolyte layer.

\subsection{Stability of enzyme immobilized membrane}

Generally, free enzyme in solution is not stable and its activity reduces gradually. One of the most important aspects to be considered in enzyme immobilization is then the stability with respect of time that it is supposed to be enhanced. The long-term stability of free and immobilized TRY and URE is shown in Figs. 8 and 9, respectively. The relative activity was calculated as referred to the initial value at the first day, multiplied by 100 . It has to be noted that samples were periodically assayed in the case of enzyme supported membranes contrary to the case of free enzyme where a fresh aliquot of solution was reacted at each given time. Strictly speaking, these experiments give indication on the stability and reusability in the case of immobilized enzyme and stability on storage for the free enzyme.

Free TRY looses about $50 \%$ of its initial activity after 40 days. This decrease in activity is assumed to be due to the autolysis of enzyme during the storage time [33]. Immobilized TRY whatever the support used for the adsorption shows better stability, which is probably due to the prevention of autolysis. We have seen before that immobilized TRY as the outer layer in the LbL self-assembly exhibits the higher catalytic activity. Data in Fig. 8 shows that these 
membranes kept approximately $60 \%$ of their initial activity after 100 days. Immobilization as the inner layer gave even a better result: the relative activity of (AN69-PEI-ALG-TRY-ALG) membrane was found to be practically stable over 100 days. Actually, the membrane only lost $5 \%$ of its initial activity after this period. Our findings suggest that the technique allows conserving the activity of immobilized enzyme and avoids its denaturation. As above mentioned, the activity test was carried out using the same samples of TRY immobilized membranes indicating that TRY retains its activity after repeated exposure to the substrate. A TRY stability increase has been reported to also occur by covalent bonding to polysaccharide [39] and to silica beads [40]. However, the effect takes place at a much lesser extent probably due to the active site modification.

Similarly, the study of stability was also investigated for the case of URE. Free URE lost almost all its activity after 25 days. This obtained result was in accordance with the literature [21]. The relative activity of the immobilized URE onto AN69 membrane decreased sharply to $5 \%$ in 5 days. Actually, the results suggest that the adsorption between both negatively charged URE and support is not very stable. On the other hand, immobilization of URE in LbL self-assembly of polyelectrolyte did not show great difference of behavior compared to the free URE with a strong decrease of activity during the first 2 weeks. After this period, it can be observed that the relative activity of immobilized URE become more or less stable. This result suggests that either two URE populations might be formed through the immobilization stage or a change into a more stable conformation slowly take place owing to the PEI layer. Thus, URE immobilized as the inner layer of polyelectrolyte (AN69-PEIURE-PEI) kept about $50 \%$ of its initial activity after 28 days. Again immobilization in between two polyelectrolyte layers seems to be more advantageous in term of stability.

\section{Conclusion}

Alternative LbL assembly, a simpler and more cost-effective technique than covalent binding, is proved to be successful to prepare catalytic TRY and URE immobilized membranes. We showed that TRY immobilization took place on the external surface and within the membrane porosity owing to its small size enabling its transport through the membrane while URE adsorption was mainly located on the surface. Calculation based on the enzyme theoretical interfacial concentration indicates that the surface available to TRY is about 75 times higher than that available to URE. One of the objectives of this work was to investigate the effect of the enzyme location in LbL assembly on their activity and stability. Although immobilization results in a decrease of enzyme activity probably due to the diffusion limited accessibility of substrates compared to the solution, we found that the $\mathrm{pH}$ dependence of the immobilized enzymes activity is similar to that of the free enzyme in solution indicating that no dramatic change in the catalytic site microenvironment occurs through the LbL assembly. Another interesting point is the strong increase of stability by immobilizing the enzyme using the LbL technique. The outer layer can consist of the enzyme or of a polyelectrolyte covering the enzyme layer. The latter architecture appears to bring the better environment to ensure long-term enzyme stability. All these data demonstrate that the LbL self-assembly of polyelectrolytes can afford a simple alternative to covalent bonding method of preparing efficient enzyme reactive membrane. It can then be envisioned to tailor the LbL building depending on the targeted application.

\section{Acknowledgments}

The authors would like to thank the Ministry of Foreign Affairs of the Republic of France and the Scientific and Technical
Research Council of Turkey for partial funding (IFC), the GambroHospal, Lyon, France for kindly providing the AN69 and AN69-PEI membranes and Didier Cot for his technical assistance in SEM observations.

\section{Appendix A. Supplementary data}

Supplementary data associated with this article can be found, in the online version, at doi:10.1016/j.memsci.2010.08.042.

\section{References}

[1] M.F. Chaplin, S. Bucke, Enzyme Technology, Cambridge University Press, UK, 1990, p. 80.

[2] K.A. Walsh, Trypsinogens and trypsins of various species, Method Enzymol. 19 (1970) 41-63.

[3] S.J. Ge, H. Bai, L.X. Zhang, Trypsin immobilization on shrimp chitin with formaldehyde and its application to continuous hydrolysis of casein, Biotechnol. Appl. Biochem. 24 (1996) 1-6.

[4] O. Kirk, T.V. Borchert, C.C. Fuglsang, Industrial enzyme applications, Curr. Opin. Biotechnol. 13 (2002) 345-435.

[5] B. Krajewska, I. Ureases, Functional, catalytic and kinetic properties: a review, J. Mol. Catal. B: Enzym. 59 (2009) 9-21.

[6] M.C. Yang, W.C. Lin, Surface modification and blood compatibility of polyacrylonitrile membrane with immobilized chitosan-heparin conjugate, J. Polym. Res. 9 (2002) 201-206.

[7] Z.-G. Wang, L.-S. Wan, Z.-K. Xu, Surface engineerings of polyacrylonitrilebased asymmetric membranes towards biomedical applications: an overview, J. Membr. Sci. 304 (2007) 8-23.

[8] G. Decher, J.D. Hong, Buildup of ultrathin multilayer films by a self-assembly process. I. Consecutive adsorption of anionic and cationc bipolar amphiphiles and polyelectrolytes on charged surfaces, Ber. Buns. Phys. Chem. 95 (1991) 1430-1434.

[9] H. Zhao, H. Ju, Multilayer membranes for glucose biosensing via layer-by-layer assembly of multiwall carbon nanotubes and glucose oxidase, Anal. Biochem. 350 (2006) 138-144.

[10] N.G. Hoogeven, M.A. Cohen-Stuart, G.J. Fleer, M.R. Böhner, Formation and stability of multilayers of polyelectrolytes, Langmuir 12 (1996) 3675-3681.

[11] G. Ladam, P. Schaad, J.-C. Voegel, P. Schaaf, G. Decher, F. Cuisinier, In situ determination of the structural properties of initially deposited polyelectrolyte multilayers, Langmuir 16 (2000) 1249-1255.

[12] N.G. Balabushevitch, G.B. Sukhorukov, N.A. Moroz, D.V.Volodkin, N.I. Larionova, E. Donath, H. Moehwald, Encapsulation of proteins by layer-by-layer adsorption of polyelectrolytes onto protein aggregates: factors regulating the protein release, Biotechnol. Bioeng. 76 (2001) 207-213.

[13] F.N. Crespilho, M.E. Ghica, M. Florescu, F.C. Nart, O.N. Oliveira Jr., C.M.A. Brett, A strategy for enzyme immobilization on layer-by-layer dendrimer-gold nanoparticle electrocatalytic membrane incorporating redox mediator, Electrochem. Commun. 8 (2006) 1665-1670.

[14] L. Caseli, D.S.D. Santos Jr., M. Foschini, D. Gonçalves, O.N. Oliveira Jr., The effect of the layer structure on the activity of immobilized enzymes in ultrathin films, J. Colloid Interface Sci. 303 (2006) 326-331.

[15] E. Garbers, R. Mitlöhner, R. Georgieva, H. Baümler, Activity of immobilized trypsin in layer structure of polyelectrolyte microcapsules (PEMC), Macomol. Biosci. 7 (2007) 1243-1249.

[16] Q.T. Nguyen, Z. Ping, T. Nguyen, P. Rigal, Simple method for immobilization of biomacromolecules onto membranes of different types, J. Membr. Sci. 213 (2003) 85-95.

[17] V. Smuleac, D.A. Butterfield, D. Bhattacharyya, Layer-by-layer-assembled microfiltration membranes for biomolecule immobilization and enzymatic catalysis, Langmuir 22 (2006) 10118-10124.

[18] S. Datta, C. Cecil, D. Bhattacharyya, Functionalized membranes by layer-bylayer assembly of polyelectrolytes and in situ polymerization of acrylic acid for applications in enzymatic catalysis, Ind. Eng. Chem. Res. 47 (2008) 4586-4597.

[19] Y. Wang, F. Caruso, Macroporous zeolitic membrane bioreactors, Adv. Funct. Mater. 14 (2004) 1012-1018.

[20] A. Yu, Z. Liang, F. Caruso, Enzyme multilayer-modified porous membranes as biocatalysts, Chem. Mater. 17 (2005) 171-175.

[21] K. Gabrovska, A. Georgieva, T. Godjevargova, O. Stoilova, N. Manolova Poly(acrylonitrile) chitosan composite membranes for urease immobilization, J. Biotechnol. 129 (2007) 674-680.

[22] S. Disawal, J. Qiu, B.B. Elmore, Y.M. Lvov, Two-Step sequential reaction catalyzed by layer-by-layer assembled urease and arginase multilayers, Colloids Surf. B 32 (2003) 145-156.

[23] B. Krajewska, Ureases. II. Properties and their customizing by enzyme immobilizations: a review, J. Mol. Catal. B: Enzym. 59 (2009) 22-40.

[24] M.M. Bradford, A rapid and sensitive method for the quantification of microgram quantities of protein utilizing the principle of protein-dye binding, Anal. Biochem. 72 (1976) 248-254.

[25] J. Ethève, P. Déjardin, M. Boissière, Adsorption of lysozyme on a hemodialysis sulfonated polyacrylonitrile membrane, with and without preadsorbed poly(ethyleneimine) on the external faces, Colloids Surf. B 28 (2003) 285-293. 
[26] J.B. Sumner, D.B. Hand, The isoelectric point of crystalline urease, J. Am. Chem. Soc. 51 (1929) 1255-1260.

[27] M. Edani, H. Imai, Automated enzyme analysis by high-perfomance liquid chromatography postcolumn substrate reaction: application to trypsin and chymotrypsin, Anal. Sci. 9 (1993) 15-17.

[28] T. Sipos, J.R. Merkel, An effect of calcium ions on the activity, heat stability, and structure of trypsin, Biochemistry 9 (1970) 2766

[29] M.W. Weatherburn, Phenol-hypochlorite reaction for determination of ammonia, Anal. Chem. 39 (1967) 971-974.

[30] K. Takishima, T. Suga, G. Mamiya, The structure of jack bean urease - the complete amino-acid sequence, limited proteolysis and reactive cysteine residues, Eur. J. Biochem. 175 (1988) 151-165.

[31] D.B. Ratner, A.S. Hoffman, F.J. Schoen, J.E. Lemons, Biomaterials Science: An Introduction to Materials in Medicine, Academic Press, 1996, p. 136.

[32] S. Koutsopoulos, K. Patzsch, W.T.E. Bosker, W. Norde, Adsorption of trypsin on hydrophilic and hydrophobic surfaces, Langmuir 23 (2007) 2000-2006.

[33] K. Hossain, C.M. Monreal, A. Sayari, Adsorption of urease on PE-MCM-41 and its catalytic effect on hydrolysis of urea, Colloids Surf. B 62 (2008) 42-50.

[34] R. Hadj Lajimi, A. Ben Abdallah, E. Ferjani, M.S. Roudesli, A. Deratani, Change of the performance properties of nanofiltration cellulose acetate membranes by surface adsorption of polyelectrolyte multilayers, Desalination 163 (2004) 193-202.

[35] S. Klomklao, S. Benjakul, W. Visessanguan, H. Kishimura, B.K. Simpson, Trypsin from the pyloric caeca of bluefish (Pomatomus saltatrix), Comp. Biochem. Physiol. B: Biochem. Mol. Biol. 148 (2007) 382-389.

[36] K.D. Johnson, A. Clark, S. Marshall, A functional comparison of ovine and porcine trypsins, Comp. Biochem. Physiol. B: Biochem. Mol. Biol. 131 (2002) 423-431.

[37] B. Krajewska, W. Zaborska, The effect of phosphate buffer in the range of pH 5.80-8.07 on jack bean urease activity, J. Mol. Catal. B: Enzym. 6 (1999) 75-81.

[38] K. Drauz, H. Waldmann, Enzyme Catalysis in Organic Synthesis, 2nd ed., WileyVCH, Weinheim, 2002, pp. 210-214.

[39] F.M.F. Monteiro, G.M.M. Silva, J.B.R. Silva, C.S. Porto, L.B. de Carvalho Jr., J.L. Lima-Filho, A.M.A. Carneiro-Leăo, M.G. Carneiro-da-Cunha, A.L.F. Porto, Immobilization of trypsin on polysaccharide film from Anacardium occidentale L. and its application as cutaneous dressing, Process Biochem. 42 (2007) 884888.
[40] F. Xi, J. Wu, Z. Jia, X. Lin, Preparation and characterization of trypsin immobilized on silica gel supported macroporous chitosan bead, Process Biochem. 40 (2005) 2833-2840.

\section{Glossary}

$A$ : absorbance value of the product

$A_{T R Y}, A_{U R E}$ : specific activity of trypsin and urease, respectively $\left(\mathrm{mmol} \mathrm{min}^{-1} \mathrm{mg}^{-1}\right)$ ALG: sodium alginate

AN69: polyacrylonitrile based membrane

BAPNA: $\mathrm{N}_{\alpha}$-benzoyl-DL-arginine- $p$-nitroanilide

$C$ : concentration of the protein $\left(\mathrm{mg} \mathrm{mL}^{-1}\right)$

IP: isoelectric point

$k_{\text {cat }}$ : turnover constant $\left(\mathrm{min}^{-1}\right)$

$K_{M}$ : enzyme-substrate complex dissociation constant (Michaelis constant) (mM)

$L b L$ : layer-by-layer technique

$m$ : mass of the adsorbed enzyme ( $\mathrm{g}$ )

$n_{\mathrm{NH}_{3}}$ : mole number of $\mathrm{NH}_{3}(\mathrm{~mol})$

PEI: polyethyleneimine

p-NA: $p$-nitroaniline

$r$ : radius of the enzyme $(\mathrm{m})$

$t$ : reaction time (min)

TRY: bovine trypsin

URE: Jack Bean urease

$v$ : reaction volume

$V_{\max }$ : maximum reaction rate $\left(\mathrm{mmol} \mathrm{min}^{-1}\right)$

Greek symbols

$\varepsilon$ : extinction coefficient of $p$-NA at $410 \mathrm{~nm}\left(\mathrm{M}^{-1} \mathrm{~cm}^{-1}\right)$

$\Gamma_{T R Y}$ and $\Gamma_{U R E}$ : interfacial concentration of trypsin and urease, respectively $\left(\mathrm{mg} \mathrm{m}^{-2}\right)$

$\Gamma_{\max }^{i}$ : maximum interfacial concentration of enzyme $\left(\mathrm{mg} \mathrm{m}^{-2}\right)$ 